\title{
AN ASSOCIATION BETWEEN CUMULATIVE EXPOSURE TO LIGHT AT NIGHT AND THE PREVALENCE OF HYPERURICEMIA IN STEEL WORKERS
}

\author{
XIAOMING LI ${ }^{1}$, XIANGHUI XU ${ }^{2}$, YANG SONG ${ }^{1}$, SHIYUE CUI ${ }^{1}$, CHAO XUE ${ }^{1}$, LIHUA WANG ${ }^{1}$, \\ JIANHUI WU ${ }^{1}$, and JUXIANG YUAN ${ }^{1}$
}

North China University of Science and Technology, Tangshan, China

${ }^{1}$ School of Public Health

${ }^{2}$ Hospital

\begin{abstract}
Objectives: Exposure to light at night (LAN) can disturb circadian endocrine and metabolic rhythms. Hyperuricemia (HUA) is an early-onset metabolic disorder. However, it is still not clear whether LAN exposure increases the prevalence of HUA. Material and Methods: The authors used crosssectional data on the Beijing-Tianjin-Hebei occupational populations cohort from March-July 2017. A total of 7664 steel workers were finally selected to investigate the relationship between LAN exposure and the prevalence of HUA among steel workers. The authors collected demographic and socio-economic data, as well as information on lifestyle factors, anthropometric measures, and laboratory tests. The restricted cubic spline method was used to analyze the dose-response relationship between cumulative LAN exposure and the prevalence of HUA. Logistic regression analyses were used to fit the relationship between them. Results: The average age of the participants was $43.5 \pm 8.6$ years; $7051(91.7 \%)$ of them were males, $2749(35.9 \%)$ reported to suffer from HUA, and $1241(16.2 \%)$ were not exposed to LAN. There was a significant non-linear dose-response relationship between them. After adjustment for the confounding factors, including demographic data, lifestyle factors, etc., the lower LAN exposure was significantly associated with HUA (0-1931.7 days, OR = 1.180, and the 95\% CI: 1.000-1.394; 1931.7-4343 days, OR = 1.215, 95\% CI: 1.035-1.426). Conclusions: This study revealed that a certain amount of exposure to LAN is independently related to the prevalence of HUA in steel workers in China. Int J Occup Med Environ Health. 2021;34(3):385-401
\end{abstract}

Key words:

uric acid, circadian rhythms, hyperuricemia, steel workers, light at night, restricted cubic spline

\section{INTRODUCTION}

Nowadays, more than one-third of the world's population are exposed to light at night (LAN) [1]. A growing number of epidemiological studies indicate that LAN is associated with various pathological changes such as sleep deprivation, circadian rhythm disruption, nocturnal melatonin suppression and metabolic disorders, as a result of which some adverse health outcomes are likely to happen, such as obesity, type 2 diabetes, cancer and cardiovascular diseases [2-4]. However, the health damage caused by longterm LAN exposure, and the relationship between LAN

Funding: this research was supported by the Ministry of Science and Technology of the People's Republic of China (project No. 2016YFC0900605 entitled "National Key R\&D Program of China," project manager: Juxiang Yuan).

Received: April 25, 2020. Accepted: October 22, 2020.

Corresponding author: Juxiang Yuan, North China University of Science and Technology, School of Public Health, 21 Bohai Road, Caofeidian Xincheng, Tangshan, Hebei, China (e-mail: yuanjx@ncst.edu.cn). 
exposure and the prevalence of hyperuricemia (HUA), have yet to be explored.

Hyperuricemia, defined as the presence of an elevated concentration of serum uric acid (SUA), has received increasing attention as a major public health problem. The prevalence of HUA ranges 11.7-19.8\% in the general population, 31.6\% in high-altitude persons in China [5-7], and 11.4-29.5\%, according to population-based epidemiological surveys, in western countries such as the USA, Italy, and Ireland, and Asian countries such as Japan and South Korea [8-11]. However, according to the previous investigation study conducted by the authors, the prevalence of HUA is high among steel workers in China, reaching 36.2\% [12].

Increasing evidence suggests that HUA is associated with metabolic disturbance and plays an important role in the development of some metabolic diseases, such as gout, hypertension, metabolic syndrome, stroke, cardiovascular diseases, and chronic kidney disease [13-15]. Meanwhile, many studies have shown that LAN exposure leads to the same adverse health outcomes by disrupting circadian rhythms and inducing metabolic disorders [16]. Therefore, it is quite likely that LAN exposure is also associated with HUA. The possible molecular biological mechanism is that LAN exposure reduces the secretion of melatonin, as well as causes oxidative stress, and increases the level of blood uric acid.

Expose to LAN is quite common among steel workers. According to the authors' previous investigation, $65.4 \%$ of steel workers perform shift work [17]. Steel workers tend to constantly work without rest during night shifts (12-5 a.m.), just like they do during day shifts, as a result of which they are exposed to artificial light throughout the night shift. Therefore, steel workers are a population facing a high risk of adverse health outcomes due to LAN exposure. Considering this, the authors formulated a hypothesis that prolonged LAN exposure is associated with an increased prevalence of HUA among steel workers in China.

In this study, steel workers coming from a large steel enterprise in China were selected as the subjects, and the as- sociation between their LAN exposure and the prevalence of HUA was investigated.

\section{MATERIAL AND METHODS}

\section{Subjects}

In this study, use was made of the baseline data of the Beijing-Tianjin-Hebei Occupational Population Health Cohort Study (JOC) in 2017. The participants came from the Tangsteel company, a large steel enterprise in the Hebei Province, northern China. All 8646 steel workers who participated in the annual occupational health examinations in March-July 2017 were recruited as potential research subjects. After excluding the subjects without available data on age, dietary habits, LAN exposure, height, weight, waist circumference, systolic blood pressure (SBP), diastolic blood pressure (DBP) and SUA, a total of 7664 eligible subjects (7051 men and 633 women) were included in the final analysis (Figure 1). All the subjects had provided their written consent before they participated in the study. The study was conducted in accordance with the Declaration of Helsinki, and the protocol was approved by the Ethics Committee of the North China University of Science and Technology (approval No. 16040).

\section{Questionnaire measurements}

Information on the socio-demographic characteristics (age, sex, educational level, marital status, nationality, and household income), lifestyle factors and behavioral habits (smoking status, alcohol consumption, dietary patterns, salt intake, physical activity, insomnia, and daily sedentary time), a family history and a medical history (hypertension, dyslipidemia, and diabetes) were collected face-to-face by well-trained investigators using a uniform questionnaire for all the participants. The smoking status, alcohol consumption, and salt intake were determined as described in the literature [18]. The smoking status was categorized as the participant's being a non-smoker, a former smoker or a current smoker; alcohol consumption was categorized as the participant's being 
a never drinker, a former drinker or a current drinker; and salt intake was categorized as low, moderate or high.

\section{Measurement of LAN exposure}

At first, the authors collected information on the monthly number of days of exposure to artificial light (i.e., at 12-5 a.m.) per worker. Then, the cumulative number of days of exposure was calculated in annual terms. The authors investigated the work history of each worker regarding every year since they had entered the company, and calculated the cumulative annual number of days of exposure. Then, the numbers of days of LAN exposure in each year were added. At last, the numbers of days of LAN exposure, equal to the sum of days of exposure per year, were obtained [19].

$$
\mathrm{LAN}=\Sigma \mathrm{T}_{1}+\mathrm{T}_{2}+\ldots+\mathrm{T}_{\mathrm{i}}
$$

where:

$\mathrm{i}$ - the years of work,

$\mathrm{T}$ - the days of annual LAN exposure.

\section{Physical activity}

The authors assessed physical activity using the Chinese version of the International Physical Activity Questionnaire (IPAQ) [20,21]. The overall physical activity level, including any activities at work and at home, as well as recreational or sports, and leisure-time activities, from the past 7 days was used to divide the participants into low-, moderate-, or high-activity categories, according to the data processing and analysis guidelines applicable to IPAQ.

\section{Insomnia}

The assessment of insomnia was based on the Athens Insomnia Scale (AIS), which is widely used in assessing insomnia in many countries [22,23]. The AIS consists of 8 items, each of which is scored on a 4-point Likert scale: from 0 pts (no problem at all) to 3 pts (very serious problem), with the total score ranging 0-24 pts. The higher scores in-

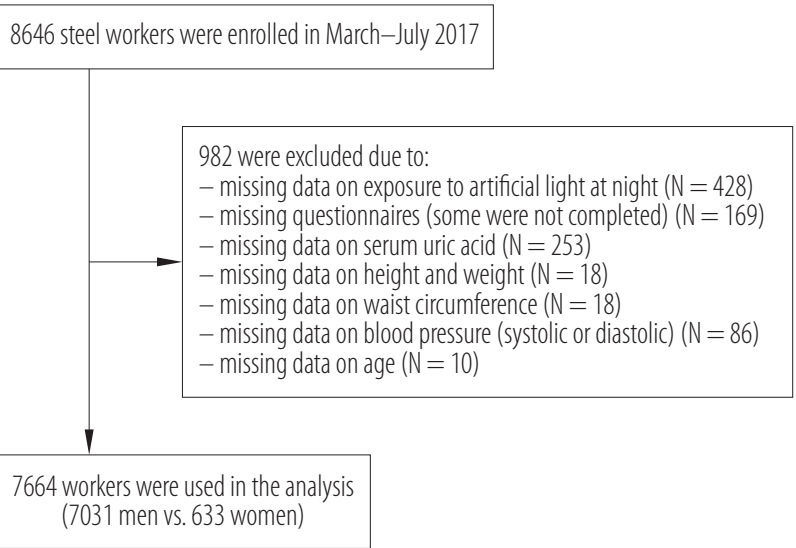

Figure 1. Flow diagram of the participants of the BeijingTianjin-Hebei Occupational Population Health Cohort Study (JOC) conducted in 2017

dicate more severe insomnia. The scoring guidelines were classified into 3 categories: non-insomnia (0-3 pts), subinsomnia (4-6 pts), and insomnia ( $\geq 7 \mathrm{pts}$ ).

\section{Diet scores}

The authors assessed the usual food intakes of the participants over the past month based on the Dietary Approaches to Stop Hypertension (DASH). The DASH diet scores make reference to individual dietary components, including 8 components: a high intake of fruit, vegetables, nuts and legumes, low-fat dairy products, and whole grains, and a low intake of sodium, sweetened beverages, and red and processed meats $[24,25]$. The DASH diet scores range $8-40$ pts according to their intake ranking.

\section{Physical examination}

Blood pressure of the participants was measured 3 times by trained personnel using the Omron digital blood pressure measuring device (HEM7135, China), on the left arm, in a sitting position, after they had rested for $10 \mathrm{~min}$. The mean value of the 3 measurements was then used in the analysis. The participants were classified as suffering from hypertension when their SBP was $\geq 140 \mathrm{~mm} \mathrm{Hg}$ and/or DBP was $\geq 90 \mathrm{~mm} \mathrm{Hg}$ [26]. Waist circumference was meas- 
ured with an inelastic tape positioned between the lowest margin of the ribs and the top of the iliac crest, to the nearest $0.1 \mathrm{~cm}$.

\section{Laboratory measurements}

After an overnight fast lasting $\geq 8 \mathrm{~h}$, the participants' blood samples were collected by trained clinical nurses. The levels of SUA (mg/dl), fasting plasma glucose (FPG, mmol/l), triglyceride (TG, mmol/l), total cholesterol (TC, mmol/l), high-density lipoprotein cholesterol (HDL-C, mmol/l), and low-density lipoprotein cholesterol (LDL-C, mmol/l) were measured with the Architect Ci8200 full automatic blood biochemical analyzer (ABBOTT Laboratories, Abbott Park, Illinois, USA) in the Hongci hospital of the Tangshan City. Hyperuricemia was defined as SUA of $\geq 420 \mu \mathrm{mol} / 1$ in males or $\geq 360 \mu \mathrm{mol} / \mathrm{l}$ in females [27], and on the basis of the previous diagnosis of gout.

Abnormal liver function was defined as aspartate aminotransferase (AST) of $>40 \mathrm{u} / \mathrm{l}$ and/or alanine aminotransferase (ALT) of $>40 \mathrm{u} / \mathrm{l}$, and/or $\gamma$-glutamyltransferase (GGT) of $>58 \mathrm{u} / \mathrm{l}$. The authors defined dyslipidemia as serum TC of $\geq 6.2 \mathrm{mmol} / \mathrm{l}$ and/or TG of $\geq 2.3 \mathrm{mmol} / \mathrm{l}$, and/ or LDL-C of $\geq 4.1 \mathrm{mmol} / \mathrm{l}$, and/or non-high-density lipoprotein cholesterol (NHDL-C) of $\geq 4.9 \mathrm{mmol} / \mathrm{l}$. Abnormal fasting blood glucose was defined as $\geq 7.0 \mathrm{mmol} / \mathrm{l}$. The selected materials and methods should contain sufficient details enabling all these procedures to be repeated.

\section{Investigation of occupational hazards in the workplace}

Data on the occupational health and safety practices of the steel workers, and the occupational hazards that they experienced in their workplaces, including dust, noise, carbon monoxide (CO), and high temperature exposure, were collected by a team of trained research assistants.

\section{Statistical analysis}

Data were analyzed using SAS 9.4 (SAS Institute Inc., Cary, NC, USA) and RStudio (Boston, MA, USA) software. Quan- titative variables with normal distributions were presented as means and standard deviations (SDs), while skewed distribution variables were reported as medians and interquartile ranges. Categorical variables were presented as numbers and percentages. Comparisons between 2 groups were made using t-tests for normally distributed variables, Wilcoxon rank-sum tests for skewed distributed variables, and $\chi^{2}$ tests for categorical data. Data on SBP, DBP, age, the body mass index (BMI), and cumulative LAN exposure were used in the Mann-Whitney U test, while other baseline characteristics were used in the $\chi^{2}$ test to compare the HUA and nonHUA groups. The restricted cubic spline (RCS) method was used to analyze the dose-response relationship of cumulative LAN exposure and HUA, and a multivariate binary logistic regression analysis was employed to analyze the relationship between cumulative LAN exposure and HUA. In addition, the OR values of the variables strongly associated with the incidence of HUA are shown on a forest map.

Random forest modeling is a computationally extensive and robust data mining technique that can accommodate large sets of proposed variables as inputs, in order to identify the factors associated with the outcome of interest using an ensemble of regression or classification trees. The importance of each variable can also be quantified by assessing the average prediction error across all random trees. The authors decided to analyze the importance of the factors influencing HUA by means of random forest modeling.

\section{RESULTS}

\section{Participants' characteristics}

The mean age of the study population was $43.5 \pm 8.6$ years, and the share of males was $91.7 \%$. The incidence of HUA in the study population was $35.9 \%$, and the average LAN exposure was 2781.9 (956.6-4502.9) days, while $16.2 \%$ of the subjects were not exposed to LAN. Compared with the nonHUA group, the subjects in the HUA group were significantly younger, and had a higher BMI, a larger waist circumference, lower DASH diet scores, a higher waist-to-hip ratio, 
Table 1. A comparison of the participants' baseline characteristics between the hyperuricemia (HUA) and non-HUA groups of steel workers, using the baseline data of the Beijing-Tianjin-Hebei Occupational Population Health Cohort Study (JOC) conducted in 2017

\begin{tabular}{|c|c|c|c|}
\hline \multirow{2}{*}{ Variable } & \multicolumn{2}{|c|}{$\begin{array}{l}\text { Participants } \\
(\mathrm{N}=7664)\end{array}$} & \multirow{2}{*}{$\mathrm{p}$} \\
\hline & $\begin{array}{l}\text { HUA group } \\
(\mathrm{N}=4915)\end{array}$ & $\begin{array}{c}\text { non-HUA group } \\
(\mathrm{N}=2749)\end{array}$ & \\
\hline Gender [n (\%)] & & & $<0.001$ \\
\hline male & $4422(90.0)$ & $2609(94.9)$ & \\
\hline female & $493(10.0)$ & $140(5.1)$ & \\
\hline Age [years] (Me (P25, P75)) & $47.0(38.0,51.0)$ & $42.0(34.0,49.0)$ & $<0.001$ \\
\hline Age $[n(\%)]$ & & & $<0.001$ \\
\hline 20-29 years & $266(5.4)$ & $271(9.9)$ & \\
\hline $30-39$ years & $1129(23.0)$ & $919(33.4)$ & \\
\hline 40-49 years & $1913(38.9)$ & $944(34.3)$ & \\
\hline$\geq 50$ years & $1607(32.7)$ & $615(22.4)$ & \\
\hline BMI $\left[\mathrm{kg} / \mathrm{m}^{2}\right](\mathrm{Me}(\mathrm{P} 25, \mathrm{P} 75))$ & $24.4(22.4,26.7)$ & $25.8(23.7,28.3)$ & $<0.001$ \\
\hline $\operatorname{BMI}[\mathrm{n}(\%)]$ & & & $<0.001$ \\
\hline$<24 \mathrm{~kg} / \mathrm{m}^{2}$ & $2146(43.7)$ & $776(28.2)$ & \\
\hline $24-27.9 \mathrm{~kg} / \mathrm{m}^{2}$ & $2053(41.8)$ & $1229(44.7)$ & \\
\hline$\geq 28 \mathrm{~kg} / \mathrm{m}^{2}$ & $716(14.5)$ & $744(27.1)$ & \\
\hline Educational level [n (\%)] & & & $<0.001$ \\
\hline low & $55(1.1)$ & $36(1.3)$ & \\
\hline medium & $3829(77.9)$ & $1964(71.4)$ & \\
\hline high & $1031(21.0)$ & $749(27.3)$ & \\
\hline Marital status [n (\%)] & & & $<0.001$ \\
\hline unmarried & $286(5.8)$ & $219(8.0)$ & \\
\hline married or others & $4629(94.2)$ & $2530(92.0)$ & \\
\hline Ethnic origin $[\mathrm{n}(\%)]$ & & & $<0.001$ \\
\hline Chinese Han population & 4455 (90.6) & $2377(86.5)$ & \\
\hline others & $460(9.4)$ & $372(13.5)$ & \\
\hline Income per capita $[\mathrm{n}(\%)]$ & & & 0.008 \\
\hline$<1333$ yuans & $1162(23.6)$ & $615(22.4)$ & \\
\hline $1333-1749$ yuans & $1296(26.4)$ & $651(23.7)$ & \\
\hline $1750-2499$ yuans & $1334(27.1)$ & $795(28.9)$ & \\
\hline$\geq 2500$ yuans & $1123(22.9)$ & $688(25.0)$ & \\
\hline Smoking status [n (\%)] & & & 0.002 \\
\hline non-smoker & $2124(43.2)$ & $1072(39.0)$ & \\
\hline former smoker & $363(7.4)$ & $217(7.9)$ & \\
\hline current smoker & $2428(49.4)$ & $1460(53.1)$ & \\
\hline
\end{tabular}


Table 1. A comparison of the participants' baseline characteristics between the hyperuricemia (HUA) and non-HUA groups of steel workers, using the baseline data of the Beijing-Tianjin-Hebei Occupational Population Health Cohort Study (JOC) conducted in 2017 - cont.

\begin{tabular}{|c|c|c|c|}
\hline \multirow{2}{*}{ Variable } & \multicolumn{2}{|c|}{$\begin{array}{c}\text { Participants } \\
(\mathrm{N}=7664)\end{array}$} & \multirow{2}{*}{$\mathrm{p}$} \\
\hline & $\begin{array}{l}\text { HUA group } \\
(\mathrm{N}=4915)\end{array}$ & $\begin{array}{l}\text { non-HUA group } \\
\quad(\mathrm{N}=2749)\end{array}$ & \\
\hline Alcohol consumption [n (\%)] & & & 0.029 \\
\hline never drinker & $2928(59.6)$ & $1569(57.1)$ & \\
\hline former drinker & $273(5.6)$ & $139(5.1)$ & \\
\hline current drinker & $1714(34.8)$ & $1041(37.8)$ & \\
\hline Physical activity [n (\%)] & & & 0.101 \\
\hline low & $53(1.1)$ & $40(1.4)$ & \\
\hline moderate & $359(7.4)$ & $234(8.5)$ & \\
\hline high & 4465 (91.6) & $2494(90.1)$ & \\
\hline DASH diet score (Me (P25, P75)) & $22.0(20.0,23.0)$ & $21.0(20.0,23.0)$ & $<0.001$ \\
\hline DASH diet score [n $(\%)]$ & & & $<0.001$ \\
\hline$<20$ & $1341(27.3)$ & $867(31.5)$ & \\
\hline $20-21$ & 1015 (20.6) & $571(20.8)$ & \\
\hline $22-23$ & $1582(32.2)$ & $884(32.2)$ & \\
\hline$\geq 24$ & $977(19.9)$ & $427(15.5)$ & \\
\hline Salt intake $[\mathrm{n}(\%)]$ & & & 0.167 \\
\hline low & $1081(22.0)$ & $559(20.3)$ & \\
\hline moderate & $2227(45.3)$ & $1248(45.4)$ & \\
\hline high & $1607(32.7)$ & $942(34.3)$ & \\
\hline Insomnia $[\mathrm{n}(\%)]$ & & & 0.423 \\
\hline non-insomnia & $1163(32.8)$ & $904(32.9)$ & \\
\hline sub-insomnia & $1657(33.7)$ & $961(35.0)$ & \\
\hline insomnia & $1645(33.5)$ & $884(32.2)$ & \\
\hline Daily sedentary time $[\mathrm{n}(\%)]$ & & & 0.410 \\
\hline low & $1491(30.3)$ & $825(30.0)$ & \\
\hline moderate & $1677(34.1)$ & $978(35.6)$ & \\
\hline high & $1747(35.5)$ & $946(34.4)$ & \\
\hline Waist circumference $[\mathrm{cm}](\mathrm{Me}(\mathrm{P} 25, \mathrm{P} 75))$ & $89.0(83.0,89.0)$ & $91.0(86.0,96.0)$ & $<0.001$ \\
\hline WHR ratio $(\mathrm{Me}(\mathrm{P} 25, \mathrm{P} 75))$ & $0.89(0.89,0.90)$ & $0.90(0.89,0.90)$ & $<0.001$ \\
\hline \multicolumn{4}{|l|}{ Blood pressure $[\mathrm{mm} \mathrm{Hg}](\mathrm{Me}(\mathrm{P} 25, \mathrm{P} 75))$} \\
\hline systolic & $128(117,138)$ & $131(119,139)$ & $<0.001$ \\
\hline diastolic & $82(75,89)$ & $84(76,89)$ & $<0.001$ \\
\hline
\end{tabular}


Table 1. A comparison of the participants' baseline characteristics between the hyperuricemia (HUA) and non-HUA groups of steel workers, using the baseline data of the Beijing-Tianjin-Hebei Occupational Population Health Cohort Study (JOC) conducted in 2017 - cont.

\begin{tabular}{|c|c|c|c|}
\hline \multirow{2}{*}{ Variable } & \multicolumn{2}{|c|}{$\begin{array}{c}\text { Participants } \\
(\mathrm{N}=7664)\end{array}$} & \multirow[b]{2}{*}{$\mathrm{p}$} \\
\hline & $\begin{array}{l}\text { HUA group } \\
(\mathrm{N}=4915)\end{array}$ & $\begin{array}{c}\text { non-HUA group } \\
(\mathrm{N}=2749)\end{array}$ & \\
\hline Abnormal liver function [n (\%)] & & & $<0.001$ \\
\hline no & $4101(83.4)$ & $1828(66.5)$ & \\
\hline yes & $814(16.6)$ & $921(33.5)$ & \\
\hline Dyslipidemia [n (\%)] & & & $<0.001$ \\
\hline no & $3634(73.9)$ & $1576(57.3)$ & \\
\hline yes & $1281(26.1)$ & $1173(42.7)$ & \\
\hline Abnormal fasting blood glucose [n (\%)] & & & 0.459 \\
\hline no & $3936(80.1)$ & $2182(79.4)$ & \\
\hline yes & $979(19.9)$ & $567(20.6)$ & \\
\hline Hypertension $[\mathrm{n}(\%)]$ & & & $<0.001$ \\
\hline no & $3743(76.2)$ & $1929(70.2)$ & \\
\hline yes & $1172(23.8)$ & $820(29.8)$ & \\
\hline \multicolumn{4}{|l|}{ Family history $[\mathrm{n}(\%)]$} \\
\hline of hypertension & & & 0.043 \\
\hline no & $3620(73.7)$ & $1974(71.8)$ & \\
\hline yes & $1295(26.3)$ & $775(28.2)$ & \\
\hline of hyperlipidemia & & & 0.269 \\
\hline no & $4695(95.5)$ & $2635(95.9)$ & \\
\hline yes & $220(4.5)$ & $114(4.1)$ & \\
\hline of diabetes & & & 0.033 \\
\hline no & $4467(90.9)$ & $2462(89.6)$ & \\
\hline yes & $448(9.1)$ & $287(10.4)$ & \\
\hline \multicolumn{4}{|l|}{ Exposure $[\mathrm{n}(\%)]$} \\
\hline level of light while sleeping at home & & & 0.932 \\
\hline darkest & $2230(45.4)$ & $1253(45.6)$ & \\
\hline middle & 1953 (39.7) & $1081(39.3)$ & \\
\hline lightest & $732(14.9)$ & $415(15.1)$ & \\
\hline high temperature & & & $<0.001$ \\
\hline no & 2567 (52.2) & 1318 (47.9) & \\
\hline yes & 2348 (47.8) & $1431(52.1)$ & \\
\hline noise & & & $<0.352$ \\
\hline no & $2423(49.3)$ & $1342(48.8)$ & \\
\hline yes & $2492(50.7)$ & 1407 (51.2) & \\
\hline
\end{tabular}


Table 1. A comparison of the participants' baseline characteristics between the hyperuricemia (HUA) and non-HUA groups of steel workers, using the baseline data of the Beijing-Tianjin-Hebei Occupational Population Health Cohort Study (JOC) conducted in 2017 - cont.

\begin{tabular}{|c|c|c|c|}
\hline \multirow{2}{*}{ Variable } & \multicolumn{2}{|c|}{$\begin{array}{l}\text { Participants } \\
(\mathrm{N}=7664)\end{array}$} & \multirow{2}{*}{$\mathrm{p}$} \\
\hline & $\begin{array}{l}\text { HUA group } \\
(\mathrm{N}=4915)\end{array}$ & $\begin{array}{l}\text { non-HUA group } \\
(\mathrm{N}=2749)\end{array}$ & \\
\hline \multicolumn{4}{|l|}{ Exposure $[\mathrm{n}(\%)]-$ cont. } \\
\hline $\mathrm{CO}$ & & & $<0.163$ \\
\hline no & $2842(57.8)$ & $1557(56.6)$ & \\
\hline yes & $2073(42.2)$ & $1192(43.4)$ & \\
\hline dust & & & $<0.001$ \\
\hline no & $1800(36.6)$ & $902(32.8)$ & \\
\hline yes & $3115(63.4)$ & $1847(67.2)$ & \\
\hline Shift work $[\mathrm{n}(\%)]$ & & & 0.003 \\
\hline never & $795(16.2)$ & $372(13.5)$ & \\
\hline former & $1076(21.9)$ & $580(21.1)$ & \\
\hline current & $3044(62.9)$ & $1797(65.4)$ & \\
\hline LAN exposure [days] (Me (P25, P75)) & $2969.2(912.5,4744.3)$ & $2505.8(1040.8,4286.7)$ & $<0.001$ \\
\hline
\end{tabular}

BMI - body mass index; CO - carbon monoxide; DASH - Dietary Approaches to Stop Hypertension; LAN - light at night; WHR - waist-to-hip ratio.

and higher levels of SBP and DBP (Table 1). In contrast, the distribution of age, sex, educational level, the marital status, ethnic origin, income per capita, the smoking status, alcohol consumption, physical activity, high temperature exposure, dust exposure, abnormal liver function, dyslipidemia, a family history of blood glucose and blood hypertension, and shift work patterns among steel workers with HUA exhibited significant differences $(\mathrm{p}<0.05)$ (Table 1$)$.

\section{Dose-response relationship between LAN and HUA}

The RCS method was used to fit the relationship between LAN exposure and the prevalence of HUA. When 4 knots $(5 \%, 35 \%, 65 \%, 95 \%)$ are located at the 5 th, 35 th, 65 th, and 95th percentiles of cumulative LAN exposure, the Akaike Information Criterion value is set at the minimum, as shown in Figure 2. The RCS figure shows that there was a significant non-linear dose-response relationship between LAN exposure and HUA (the overall correlation test $=10.7$, $\mathrm{p}<0.05$, the non-linear correlation test $=8.5, \mathrm{p}<0.05$ ). It can be noted that cumulative LAN exposure and HUA show different trends, with the tangent points of cumulative LAN exposure being 1931 and 4343. Therefore, the cumulative LAN exposure was divided into 4 groups (0, 0-1931.7, $1931.7-4343$, and $\geq 4343$ days). Figure 3 shows the prevalence of HUA in the 4 cumulative LAN exposure groups.

\section{Multivariate regression analysis}

The results of logistic regression analyses are presented in Table 2. There was a statistically significant association between cumulative LAN exposure lasting <4343 days and HUA. More specifically, the unadjusted OR of LAN exposure in the 0-1931.7 group equaled 1.540 (95\% CI: 1.323-1.790), and in the 1931.7-4343 group - 1.265 (95\% CI: 1.096-1.461). After adjustments for age, sex, the educational level, the marital status, nationality, and income per capita (model 2), the OR of LAN exposure in the 0-1931.7 group was 1.238 


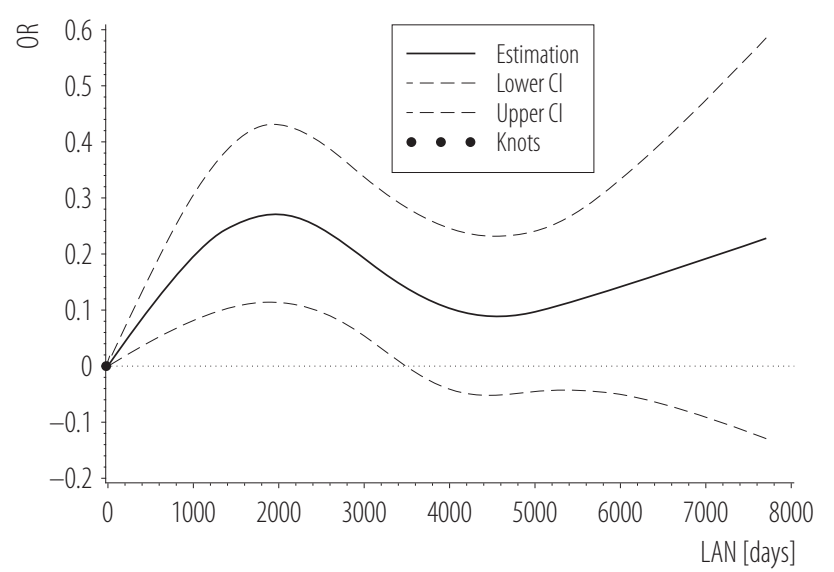

OR - the reference value for LAN is 1 .

Adjusted for age, sex, educational level, marital status, ethnic origin, income per capita, smoking status, alcohol consumption, physical activity, Dietary Approaches to Stop Hypertension diet score, insomnia, body mass index, light exposure in daily life, abnormal liver function, dyslipidemia, abnormal fasting blood glucose, hypertension, daily sedentary time, high temperature exposure, dust exposure, carbon monoxide exposure, noise exposure, a history of hypertension and diabetes, and waist circumference, in the steel workers.

Figure 2. Restricted cubic spline (RCS) of the cumulative light at night (LAN) exposure and prevalence of hyperuricemia (HUA) based on the baseline data of the Beijing-Tianjin-Hebei Occupational Population Health Cohort Study (JOC) conducted in 2017

(95\% CI: 1.057-1.451), and in the 1931.7-4343 group - 1.224 (95\% CI: 1.053-1.422). Further adjustments were made for salt intake, DASH diet scores, the smoking status, alcohol intake, daily sedentary time, physical activity, insomnia, and LAN at home (model 3), as well as adjustments for CO exposure, high temperature exposure, noise exposure, and dust exposure, based on model 3 (model 4), but the results were similar to the crude OR (95\% CI) values.

In the full model, after adjustments for BMI, waist circumference, abnormal liver function, dyslipidemia, hypertension, abnormal fasting blood glucose, a family history of hypertension, a family history of hyperlipidemia, and a family history of diabetes, based on model 4 , the OR of LAN exposure in the 0-1931.7 group reached 1.180 (95\% CI: 1.000-1.394), and in the 1931.7-4343 group it was 1.215 (95\% CI: 1.035-1.426). However, no significant

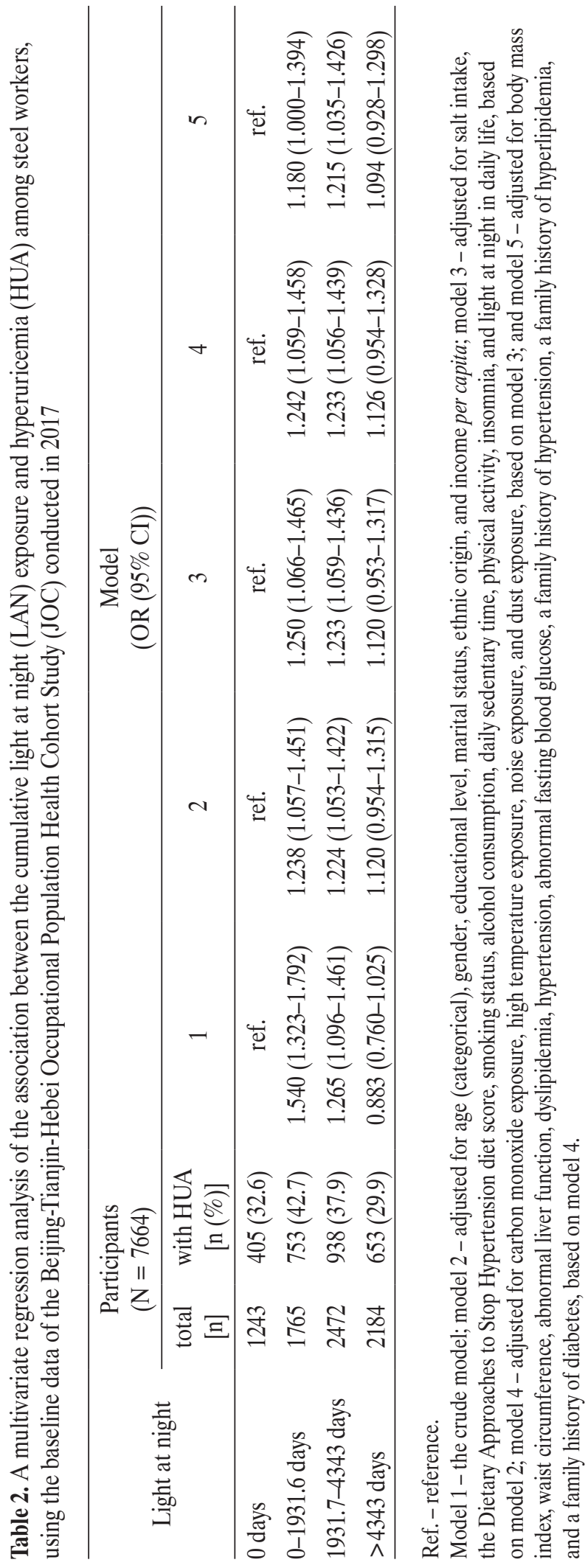




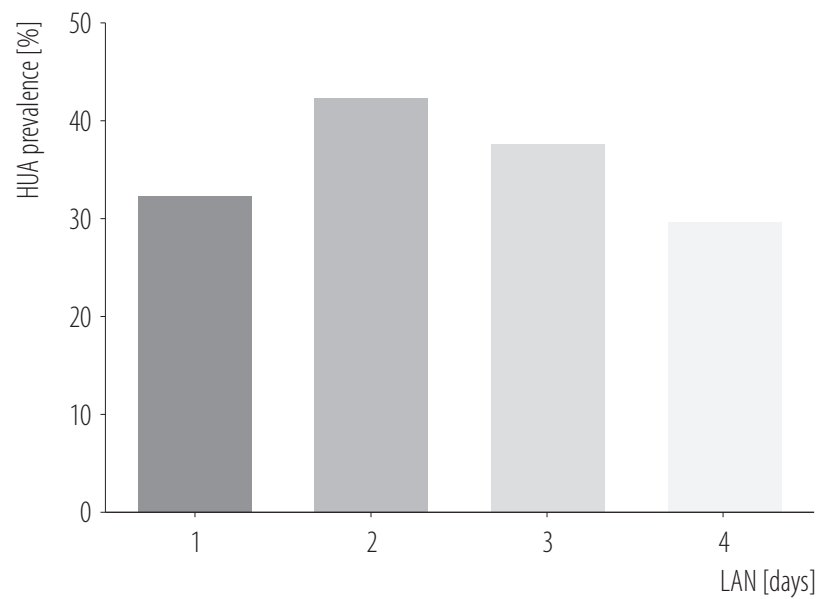

LAN1 - the value of cumulative LAN exposure equal to 0;

LAN2 - the value of cumulative LAN exposure 0-1931.6 days;

LAN3 - the value of cumulative LAN exposure 1931.7-4343 days;

LAN4 - the value of cumulative LAN exposure $>4343$ days.

Figure 3. Prevalence of hyperuricemia (HUA) in different groups of cumulative light at night (LAN) exposure based on the baseline data of the Beijing-Tianjin-Hebei Occupational Population Health Cohort Study (JOC) conducted in 2017

a Educational level was observed between LAN exposure lasting >4343 days and the prevalence of HUA, with or without adjustments for the confounders.

The authors used the random forest method to rank the importance of individual HUA factors. As shown in Figure 4, LAN exposure ranked fourth. The factors of the prevalence of HUA were further analyzed, and it was found that age, gender, BMI, waist circumference, abnormal liver function, dyslipidemia, abnormal fasting blood glucose, and Hypertension were all significant factors (Figure 5 and Table 3). However, in analyzing the subgroups divided by age, the authors did not find evidence that cumulative LAN exposure was related to HUA among different age groups (Table 4).

\section{DISCUSSION}

This study revealed that LAN exposure was associated with the prevalence of HUA in steel workers. However, it was different from the hypothesis that had been formu-

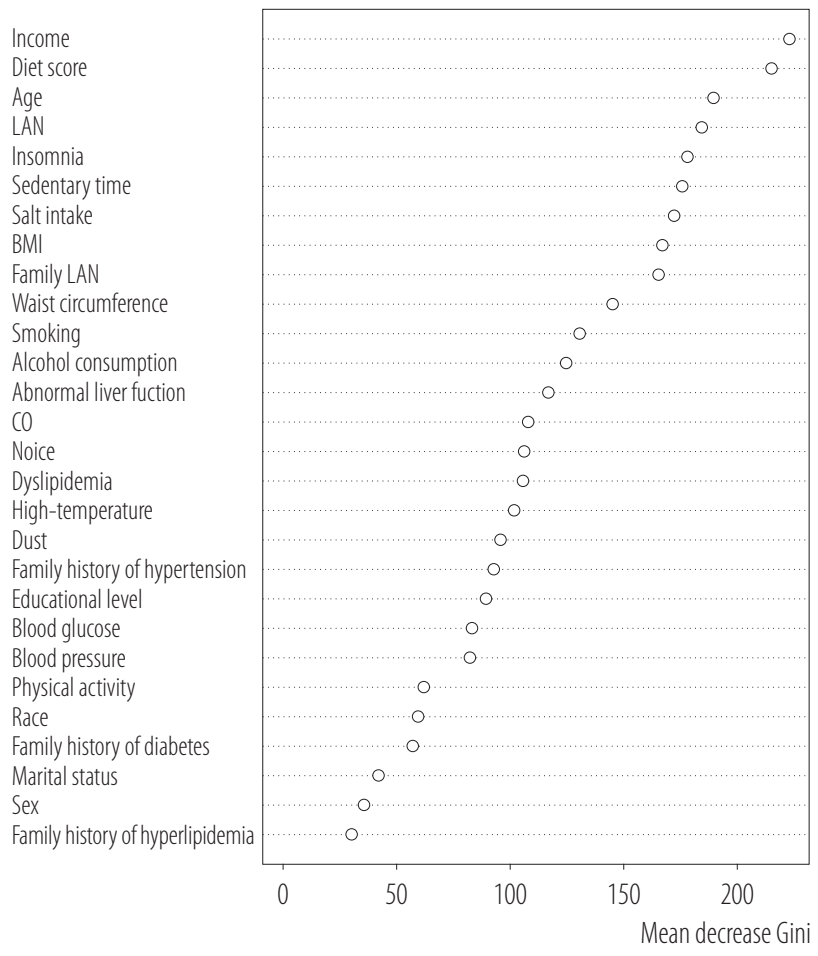

LAN - light at night.

Figure 4. The importance ranking of influencing factors based on the random forest using the baseline data of the BeijingTianjin-Hebei Occupational Population Health Cohort Study (JOC) conducted in 2017

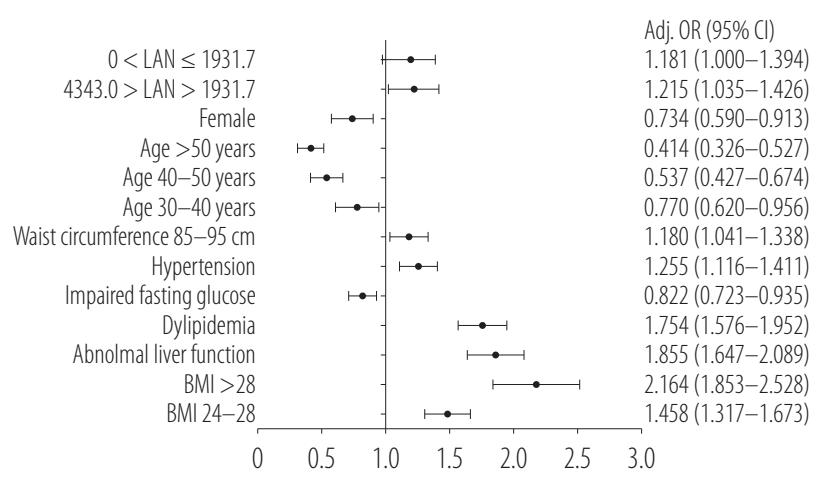

Figure 5. The significant factors of prevalence of hyperuricemia based on the baseline data of the Beijing-Tianjin-Hebei Occupational Population Health Cohort Study (JOC) conducted in 2017

lated before this study. The authors could not establish the trend that the long-term LAN exposure was linearly 
Table 3. The association between the participants' baseline characteristics and hyperuricemia (HUA) among steel workers, using the baseline data of the Beijing-Tianjin-Hebei Occupational Population Health Cohort Study (JOC) conducted in 2017

\begin{tabular}{|c|c|c|c|}
\hline Variable & $\begin{array}{l}\text { Participants with HUA } \\
(\mathrm{N}=2749) \\
{[\mathrm{n}(\%)]}\end{array}$ & OR $(95 \% \mathrm{CI})$ & $\mathrm{p}$ \\
\hline Gender & & & $<0.001$ \\
\hline male & $2609(94.9)$ & ref. & \\
\hline female & $140(5.1)$ & $0.734(0.590-0.913)$ & 0.005 \\
\hline \multicolumn{4}{|l|}{ Age } \\
\hline 20-29 years & $271(9.9)$ & ref. & \\
\hline $30-39$ years & $919(33.4)$ & $0.770(0.620-0.956)$ & 0.031 \\
\hline 40-49 years & $944(34.3)$ & $0.537(0.427-0.674)$ & $<0.001$ \\
\hline$\geq 50$ years & $615(22.4)$ & $0.414(0.326-0.527)$ & $<0.001$ \\
\hline \multicolumn{4}{|l|}{ BMI } \\
\hline$<24 \mathrm{~kg} / \mathrm{m}^{2}$ & $776(28.2)$ & ref. & \\
\hline $24-27.9 \mathrm{~kg} / \mathrm{m}^{2}$ & $1229(44.7)$ & 1.485 (1.317-1.673) & $<0.001$ \\
\hline$\geq 28 \mathrm{~kg} / \mathrm{m}^{2}$ & $744(27.1)$ & $2.164(1.853-2.528)$ & $<0.001$ \\
\hline \multicolumn{4}{|l|}{ Educational level } \\
\hline low & $36(1.3)$ & ref. & \\
\hline medium & $1964(71.4)$ & $0.693(0.441-1.090)$ & 0.082 \\
\hline high & $749(27.3)$ & $0.777(0.487-0.241)$ & 0.119 \\
\hline Marital status & & & $<0.001$ \\
\hline unmarried & $219(8.0)$ & ref. & \\
\hline married or other & $2530(92.0)$ & $0.892(0.722-1.101)$ & 0.324 \\
\hline \multicolumn{4}{|l|}{ Ethnic origin } \\
\hline Chinese Han population & $2377(86.5)$ & ref. & \\
\hline other & $372(13.5)$ & $0.854(0.727-1.002)$ & 0.060 \\
\hline \multicolumn{4}{|l|}{ Income per capita } \\
\hline$<1333$ yuans & $615(22.4)$ & ref. & \\
\hline $1333-1749$ yuans & $651(23.7)$ & $1.004(0.869-1.160)$ & 0.940 \\
\hline $1750-2499$ yuans & $795(28.9)$ & $1.144(0.993-1.318)$ & 0.053 \\
\hline$\geq 2500$ yuans & $688(25.0)$ & $0.150(0.992-1.333)$ & 0.064 \\
\hline Smoking status & & & 0.002 \\
\hline non-smoker & $1072(39.0)$ & ref. & \\
\hline former smoker & $217(7.9)$ & $1.197(0.971-1.475)$ & 0.078 \\
\hline current smoker & $1460(53.1)$ & $1.022(0.912-1.144)$ & 0.728 \\
\hline \multicolumn{4}{|l|}{ Alcohol consumption } \\
\hline never drinker & $1569(57.1)$ & ref. & \\
\hline former drinker & $139(5.1)$ & $0.829(0.650-1.058)$ & 0.156 \\
\hline current drinker & $1041(37.8)$ & $1.090(0.973-1.220)$ & 0.145 \\
\hline
\end{tabular}


Table 3. The association between the participants' baseline characteristics and hyperuricemia (HUA) among steel workers, using the baseline data of the Beijing-Tianjin-Hebei Occupational Population Health Cohort Study (JOC) conducted in 2017 - cont.

\begin{tabular}{|c|c|c|c|}
\hline Variable & $\begin{array}{l}\text { Participants with HUA } \\
\qquad(\mathrm{N}=2749) \\
{[\mathrm{n}(\%)]}\end{array}$ & OR $(95 \% \mathrm{CI})$ & $\mathrm{p}$ \\
\hline \multicolumn{4}{|l|}{ Physical activity } \\
\hline low & $40(1.4)$ & ref. & \\
\hline moderate & $234(8.5)$ & $0.883(0.551-1.416)$ & 0.604 \\
\hline high & $2494(90.1)$ & $0.816(0.524-1.271)$ & 0.367 \\
\hline \multicolumn{4}{|l|}{ DASH diet score } \\
\hline$<20$ & $867(31.5)$ & ref. & \\
\hline $20-21$ & $571(20.8)$ & $0.920(0.797-1.062)$ & 0.279 \\
\hline $22-23$ & $884(32.2)$ & $0.990(0.870-1.126)$ & 0.906 \\
\hline$\geq 24$ & $427(15.5)$ & $0.855(0.731-1.001)$ & 0.055 \\
\hline \multicolumn{4}{|l|}{ Salt intake } \\
\hline low & $559(20.3)$ & ref. & \\
\hline moderate & $1248(45.4)$ & $0.973(0.853-1.110)$ & 0.689 \\
\hline high & $942(34.3)$ & $0.912(0.792-1.051)$ & 0.215 \\
\hline \multicolumn{4}{|l|}{ Insomnia } \\
\hline non-insomnia & $904(32.9)$ & ref. & \\
\hline sub-insomnia & $961(35.0)$ & $1.057(0.935-1.195)$ & 0.322 \\
\hline insomnia & $884(32.2)$ & $0.996(0.879-1.129)$ & 0.960 \\
\hline \multicolumn{4}{|l|}{ Daily sedentary time } \\
\hline low & $825(30.0)$ & ref. & \\
\hline moderate & $978(35.6)$ & $1.024(0.905-1.158)$ & 0.674 \\
\hline high & $946(34.4)$ & $0.946(0.832-1.075)$ & 0.471 \\
\hline \multicolumn{4}{|l|}{ Abnormal liver function } \\
\hline no & $1828(66.5)$ & ref. & \\
\hline yes & $921(33.5)$ & $1.855(1.647-2.089)$ & $<0.001$ \\
\hline \multicolumn{4}{|l|}{ Dyslipidemia } \\
\hline no & $1576(57.3)$ & ref. & \\
\hline yes & $1173(42.7)$ & $1.754(1.576-1.952)$ & $<0.001$ \\
\hline \multicolumn{4}{|l|}{ Abnormal fasting blood glucose } \\
\hline no & $2182(79.4)$ & ref. & \\
\hline yes & $567(20.6)$ & $0.822(0.723-0.935)$ & 0.003 \\
\hline \multicolumn{4}{|l|}{ Hypertension } \\
\hline no & $1929(70.2)$ & ref. & \\
\hline yes & $820(29.8)$ & $1.255(1.116-1.411)$ & $<0.001$ \\
\hline \multicolumn{4}{|l|}{$\begin{array}{l}\text { Family history } \\
\text { of hypertension }\end{array}$} \\
\hline no & $1974(71.8)$ & ref. & \\
\hline yes & $775(28.2)$ & $1.088(0.967-1.224)$ & 0.187 \\
\hline
\end{tabular}


Table 3. The association between the participants' baseline characteristics and hyperuricemia (HUA) among steel workers, using the baseline data of the Beijing-Tianjin-Hebei Occupational Population Health Cohort Study (JOC) conducted in 2017 - cont.

\begin{tabular}{|c|c|c|c|}
\hline Variable & $\begin{array}{l}\text { Participants with HUA } \\
(\mathrm{N}=2749) \\
{[\mathrm{n}(\%)]}\end{array}$ & OR $(95 \% \mathrm{CI})$ & $\mathrm{p}$ \\
\hline \multicolumn{4}{|l|}{$\begin{array}{l}\text { Hypertension - cont. } \\
\text { of hyperlipidemia }\end{array}$} \\
\hline no & $2635(95.9)$ & ref. & \\
\hline yes & $114(4.1)$ & $0.823(0.636-1.066)$ & 0.146 \\
\hline \multicolumn{4}{|l|}{ of diabetes } \\
\hline no & $2462(89.6)$ & ref. & \\
\hline yes & $287(10.4)$ & $1.126(0.948-1.338)$ & 0.166 \\
\hline \multicolumn{4}{|l|}{ Waist circumference } \\
\hline$<85 \mathrm{~cm}$ & $650(23.7)$ & ref. & \\
\hline $85-95 \mathrm{~cm}$ & $1379(49.1)$ & $1.180(1.041-1.338)$ & 0.010 \\
\hline$>95 \mathrm{~cm}$ & $720(26.2)$ & $1.152(0.981-1.352)$ & 0.085 \\
\hline \multicolumn{4}{|l|}{ Exposure } \\
\hline \multicolumn{4}{|c|}{ level of light while sleeping at home } \\
\hline darkest & $1253(45.6)$ & ref. & \\
\hline middle & $1081(39.3)$ & $1.001(0.898-1.115)$ & 0.974 \\
\hline lightest & $415(15.1)$ & $0.988(0.852-1.147)$ & 0.854 \\
\hline \multicolumn{4}{|l|}{ high temperature } \\
\hline no & $1318(47.9)$ & ref. & \\
\hline yes & $1431(52.1)$ & $1.076(0.970-1.195)$ & 0.096 \\
\hline \multicolumn{4}{|l|}{ noise } \\
\hline no & $1342(48.8)$ & ref. & \\
\hline yes & $1407(51.2)$ & $0.938(0.843-1.043)$ & 0.303 \\
\hline \multicolumn{4}{|l|}{$\mathrm{CO}$} \\
\hline no & $1557(56.6)$ & ref. & \\
\hline yes & $1192(43.4)$ & $1.025(0.926-1.136)$ & 0.697 \\
\hline \multicolumn{4}{|l|}{ dust } \\
\hline no & $902(32.8)$ & ref. & \\
\hline yes & $1847(67.2)$ & 1.109 (0.993-1.238) & 0.067 \\
\hline \multicolumn{4}{|l|}{ LAN exposure } \\
\hline 0 days & & ref. & \\
\hline 0-1931.6 days & & $1.181(1.000-1.394)$ & 0.050 \\
\hline 1931.7-4343 days & & $1.215(1.035-1.426)$ & 0.017 \\
\hline >4343 days & & $1.094(0.922-1.298)$ & 0.305 \\
\hline
\end{tabular}

Ref. - reference.

Abbreviations as in Table 1. 
Table 4. The association between light at night (LAN) and hyperuricemia according to age, sex, and body mass index (BMI) among 7664 steel workers, using the baseline data of the Beijing-Tianjin-Hebei Occupational Population Health Cohort Study (JOC) conducted in 2017

\begin{tabular}{lcccc}
\hline \multirow{2}{*}{ Variable } & \multicolumn{3}{c}{$\begin{array}{c}\text { LAN } \\
(\text { OR }(95 \% \text { CI }))\end{array}$} \\
\cline { 2 - 5 } & 0 days & $0-1931.7$ days & $1931.8-4343.0$ days & $>4343.0$ days \\
\hline Age & & & & \\
$20-29$ years & ref. & $1.196(0.762-1.875)$ & $1.573(0.682-3.630)$ & $0.676(0.032-14.475)$ \\
$30-39$ years & ref. & $1.269(0.937-1.720)$ & $1.092(0.802-1.486)$ & $1.992(0.775-5.121)$ \\
$40-49$ years & ref. & $1.028(0.748-1.411)$ & $1.241(0.954-1.615)$ & $1.023(0.781-1.341)$ \\
$\geq 50$ years & ref. & $1.123(0.773-1.631)$ & $1.161(0.833-1.618)$ & $1.143(0.860-1.519)$ \\
Sex & & & & \\
male & ref. & $1.160(0.977-1.378)$ & $1.190(1.006-1.407)$ & $1.132(0.941-1.352)$ \\
BMI & & & & \\
$<24 \mathrm{~kg} / \mathrm{m}^{2}$ & ref. & $1.430(1.090-1.901)$ & $1.441(1.093-1.901)$ & $0.989(0.729-1.352)$ \\
$24-27.9 \mathrm{~kg} / \mathrm{m}^{2}$ & ref. & $1.131(0.877-1.458)$ & $1.161(0.912-1.477)$ & $1.116(0.869-1.434)$ \\
$\geq 28 \mathrm{~kg} / \mathrm{m}^{2}$ & ref. & $0.823(0.450-1.505)$ & $0.840(0.461-1.529)$ & $0.801(0.436-1.472)$ \\
\hline
\end{tabular}

Ref. - reference value.

Adjusted for age (except the age group), sex (except the sex group), educational level, marital status, ethnic origin, income per capita, smoking status, alcohol consumption, physical activity, Dietary Approaches to Stop Hypertension diet score, insomnia, BMI (except the BMI group), light exposure in daily life, abnormal liver function, dyslipidemia, abnormal fasting blood glucose, hypertension, daily sedentary time, high temperature exposure, dust exposure, carbon monoxide exposure, noise exposure, a history of hypertension and diabetes, and waist circumference, in the steel workers.

correlated with the prevalence of HUA. The dose-response curve showed that the prevalence of HUA in steel workers was parabolic, i.e., it first increased and then decreased. Compared with workers with no LAN exposure, workers with a low cumulative dose of LAN exposure (0-1931.7) had a risk of $18.8 \%$ (95\% CI: 1.000 $1.394)$, those with a medium cumulative dose of LAN exposure (1931.7-4343.0) had a risk of 21.5\% (95\% CI: 1.035-1.426), while those with a high cumulative dose of LAN exposure $(>4343)$ revealed no statistically significant difference $(\mathrm{p}>0.05)$.

These results confirm once more that LAN exposure is harmful to human health, thus being largely consistent with previous studies. For example, in a study involving 43722 American women, exposure to artificial LAN (ALAN) was proven to constitute a risk factor for weight gain and the development of overweight or obesity [5]. In a study on elderly Japanese individuals, exposure to ALAN was objectively determined using a measure of luminescence, and exposure to LAN of $\geq 3$ lux was associated with higher body weight and BMI [28]. The Heijōkyō cohort studies also showed that bedroom LAN intensity had a clear and significant association with subclinical carotid atherosclerosis [29]. In a prospective analysis of 105000 UK women, LAN exposure was not associated with an increased the risk of subsequent breast cancer [30].

Obviously, there were few reports that LAN exposure did not lead to adverse health effects. Some reasons for this difference are provided below. First, most of such studies of LAN exposure did not calculate the accumulation of exposure time, but they merely analyzed the exposure status or exposure intensity of LAN, hence the lack of the effects 
of long-term LAN exposure. Second, it is possible that long-term LAN exposure results in a physiological adaptation to LAN exposure and decreases the prevalence of HUA. Third, in steel workers, and especially in older ones, the healthy worker effect cannot be excluded.

This study showed that the dose-response relationship between cumulative LAN exposure and the prevalence of HUA is a parabolic (rather than rising) curve. Again, some reasons for this can be given. First, the workers who suffer from a high cumulative amount of LAN exposure are older and have a longer period of service, while several epidemiological studies have reported that the prevalence of HUA in men decreases gradually with age $[11,14,26]$. Second, it is related to the work task of steel workers, most of them being engaged in heavy manual labor. Some patients with gout leave their original posts, which also has some health effects. Third, after a long period of exposure to LAN, the biological rhythm is reversed, and the endocrine system of the body gradually adapts to the working environment involving LAN exposure.

There are several limitations associated with this study. First, this was a cross-sectional study, so it was impossible to explore the causal effect between LAN and HUA. Second, the authors did not measure LAN intensity which might lead to a biased estimation of the effect of LAN exposure on HUA. It is possible that LAN intensity varies at different workshops. Third, this study involved non-random sampling because the participants were recruited from a steel company located in a heavily industrial city in northern China, so the results of this study are limited when it comes to the generalization to all Chinese steel workers.

\section{CONCLUSIONS}

The findings of this study showed a significant association between a certain amount of cumulative LAN exposure and the prevalence of HUA in steel workers in China. It appears extremely significant to establish some policy and measures for the prevention of HUA.

\section{REFERENCES}

1. Falchi F, Cinzano P, Duriscoe D, Kyba CC, Elvidge CD, Baugh $\mathrm{K}$, et al. The new world atlas of artificial night sky brightness. Sci Adv. 2016;2(6):e1600377, https://doi.org/10. 1126/sciadv.1600377.

2. McFadden E, Jones ME, Schoemaker MJ, Ashworth A, Swerdlow AJ. The relationship between obesity and exposure to light at night: cross-sectional analyses of over 100,000 women in the Breakthrough Generations Study. Am J Epidemiol. 2014;180(3):245-50, https://doi.org/10.1093/aje/kwu117.

3. Stevens RG, Zhu Y. Electric light, particularly at night, disrupts human circadian rhythmicity: is that a problem? Philos Trans R Soc Lond B Biol Sci. 2015;370(1667):20140120, https://doi.org/10.1098/rstb.2014.0120.

4. Rybnikova NA, Haim A, Portnov BA. Is prostate cancer incidence worldwide linked to artificial light at night exposures? Review of earlier findings and analysis of current trends. Arch Environ Occup Health. 2017;72(2):111-22, https://doi.org/ 10.1080/19338244.2016.1169980.

5. Park YM, White AJ, Jackson CL, Weinberg CR, Sandler DP. Association of Exposure to Artificial Light at Night While Sleeping With Risk of Obesity in Women. JAMA Intern Med. 2019;179(8):1061-71, https://doi.org/10.1001/jamainternmed. 2019.0571 .

6. Dong X, Zhang H, Wang F, Liu X, Yang K, Tu R, et al. Epidemiology and prevalence of hyperuricemia among men and women in Chinese rural population: The Henan Rural Cohort Study. Mod Rheumatol. 2019:1-11, https://doi.org/10. 1080/14397595.2019.1660048.

7. Yang WX, Ma Y, Hou YL, Wang YB, You CG. Prevalence of Hyperuricemia and its Correlation with Serum Lipids and Blood Glucose in Physical Examination Population in 20152018: a Retrospective Study. Clin Lab. 2019;65(8), https://doi. org/10.7754/Clin.Lab.2019.190338.

8. Kumar AUA, Browne LD, Li X, Adeeb F, Perez-Ruiz F, Fraser $\mathrm{AD}$, et al. Temporal trends in hyperuricaemia in the Irish health system from 2006-2014: A cohort study. PLoS One. 2018;13(5): e0198197, https://doi.org/10.1371/journal.pone.0198197. 
9. Nagahama K, Inoue T, Kohagura K, Ishihara A, Kinjo K, Ohya Y. Hyperuricemia predicts future metabolic syndrome: a 4-year follow-up study of a large screened cohort in Okinawa, Japan. Hypertens Res. 2014;37(3):232-8, https://doi.org/ 10.1038/hr.2013.137.

10. Trifiro G, Morabito P, Cavagna L, Ferrajolo C, Pecchioli S, Simonetti M, et al. Epidemiology of gout and hyperuricaemia in Italy during the years 2005-2009: a nationwide population-based study. Ann Rheum Dis. 2013;72(5):694-700, https://doi.org/10.1136/annrheumdis-2011-201254.

11. Kim Y, Kang J, Kim GT. Prevalence of hyperuricemia and its associated factors in the general Korean population: an analysis of a population-based nationally representative sample. Clin Rheumatol. 2018;37(9):2529-38, https://doi.org/10.1007/ s10067-018-4130-2.

12. Zhang SK, Yang L, Zhang LY, Wang YB, Yuan JX. [Doseresponse relationship between shift work and hyperuricemia]. Chin J Dis Control Prev. 2018;22(11):1123-7, https:// doi.org/10.16462/j.cnki.zhjbkz.2018.11.008. Chinese.

13. Tao M, Pi X, Ma X, Shi Y, Zhang Y, Gu H, et al. Relationship between serum uric acid and clustering of cardiovascular disease risk factors and renal disorders among Shanghai population: a multicentre and cross-sectional study. BMJ Open. 2019;9(3):e025453, https://doi.org/10.1136/bmjopen-2018-02 5453.

14. Qiu L, Cheng XQ, Wu J, Liu JT, Xu T, Ding HT, et al. Prevalence of hyperuricemia and its related risk factors in healthy adults from Northern and Northeastern Chinese provinces. BMC Public Health. 2013;13:664, https://doi. org/10.1186/1471-2458-13-664.

15. Bardin T, Richette P. Definition of hyperuricemia and gouty conditions. Curr Opin Rheumatol.2014;26(2):186-91, https:// doi.org/10.1097/BOR.0000000000000028.

16. McMullan CJ, Rimm EB, Schernhammer ES, Forman JP. A nested case-control study of the association between melatonin secretion and incident myocardial infarction. Heart. 2017;103(9):694-701, https://doi.org/10.1136/ heartjnl-2016-310098.
17. Gao XJ, Fan HM, Cong LX, Lu Y, Ma CQ, Liao YJ, et al. [Relationships of exposures to noise, high temperature, and shift work with high-normal blood pressure and hypertension in male steel workers]. J Environ Occup Med. 2017;34(9):765-71, https://doi.org/10.13213/j.cnki.jeom.2017.17213. Chinese.

18. He H, Pan L, Pa L, Cui Z, Ren X, Wang D, et al. Data Resource Profile: The China National Health Survey (CNHS). Int J Epidemiol. 2018;47(6):1734-5f, https://doi.org/10.1093/ije/dyy151.

19. Zhou F, Shrestha A, Mai S, Tao Z, Li J, Wang Z, et al. Relationship between occupational noise exposure and hypertension: A cross-sectional study in steel factories. Am J Ind Med. 2019;62(11):961-8, https://doi.org/10.1002/ajim.23034.

20. Fan MY, Lu Jun, He PP. [Chinese guidelines for data processing and analysis concerning the International Physical Activity Questionnaire] . Chin J Epidemiology. 2014;35(8):961-4, https:// doi.org/10.3760/cma.j.issn.0254-6450.2014.08.019. Chinese.

21. Ren YJ, Su M, Liu QM, Tan YY, Du YK, Li LM, et al. Validation of the Simplified Chinese-character Version of the International Physical Activity Questionnaire-Long Form in Urban Community-dwelling Adults: a Cross-sectional Study in Hangzhou, China. Biomed Environ Sci. 2017;30(4):25563, https://doi.org/10.3967/bes2017.035.

22. Okajima I, Nakajima S, Kobayashi M, Inoue Y. Development and validation of the Japanese version of the Athens Insomnia Scale. Psychiatry Clin Neurosci. 2013;67(6):420-5, https://doi.org/10.1111/pcn.12073.

23. Chung KF, Kan KK, Yeung WF. Assessing insomnia in adolescents: comparison of Insomnia Severity Index, Athens Insomnia Scale and Sleep Quality Index. Sleep Med. 2011;12(5): 463-70, https://doi.org/10.1016/j.sleep.2010.09.019.

24. Rai SK, Fung TT, Lu N, Keller SF, Curhan GC, Choi HK. The Dietary Approaches to Stop Hypertension (DASH) diet, Western diet, and risk of gout in men: prospective cohort study. BMJ. 2017;357:j1794, https://doi.org/10.1136/ bmj.j1794.

25. Fung TT, Chiuve SE, McCullough ML, Rexrode KM, Logroscino G, Hu FB. Adherence to a DASH-style diet and risk of coronary heart disease and stroke in women. Arch In- 
tern Med. 2008;168(7):713-20, https://doi.org/10.1001/archinte. 168.7.713.

26. Liu L, Lou S, Xu K, Meng Z, Zhang Q, Song K. Relationship between lifestyle choices and hyperuricemia in Chinese men and women. Clin Rheumatol. 2013;32(2):233-9, https://doi. org/10.1007/s10067-012-2108-z.

27. Multi-Disciplinary Expert Task Force on H, Its Related D. [Chinese multi-disciplinary consensus on the diagnosis and treatment of hyperuricemia and its related diseases]. Zhonghua Nei Ke Za Zhi. 2017;56(3):235-48, https://doi. org/10.3760/cma.j.issn.0578-1426.2017.03.021. Chinese.

28. Obayashi K, Saeki K, Iwamoto J, Okamoto N, Tomioka K, Nezu S, et al. Exposure to light at night, nocturnal urinary mela- tonin excretion, and obesity/dyslipidemia in the elderly: a crosssectional analysis of the HEIJO-KYO study. J Clin Endocrinol Metab. 2013;98(1):337-44, https://doi.org/10.1210/jc.2012-2874. 29. Obayashi K, Yamagami Y, Tatsumi S, Kurumatani N, Saeki K. Indoor light pollution and progression of carotid atherosclerosis: A longitudinal study of the HEIJO-KYO cohort. Environ Int. 2019;133(Pt B):105184, https://doi. org/10.1016/j.envint.2019.105184.

30. Johns LE, Jones ME, Schoemaker MJ, McFadden E, Ashworth A, Swerdlow AJ. Domestic light at night and breast cancer risk: a prospective analysis of 105000 UK women in the Generations Study. Br J Cancer. 2018;118(4):600-6, https://doi.org/10.1038/bjc.2017.359.

This work is available in Open Access model and licensed under a Creative Commons Attribution-NonCommercial 3.0 Poland License - http://creativecommons.org/ licenses/by-nc/3.0/pl/deed.en. 